com correção de Bonferroni, 1-way ANOVA seguida de testes post-hoc segundo Tukey, testes ANOVA e T-test para medições repetidas. Aceitou-se o nível de significância de 5\%. Resultados: As resinas impressas obtiveram valores inferiores de microdureza, antes e após envelhecimento térmico e químico, relativamente às termopolimerizáveis. Comparando as resinas de igual fabrico, não se verificaram diferenças estatisticamente significativas. A avaliação do efeito dos envelhecimentos demonstrou que a Denture 3D, Probase Hot e Villacryl H Rapid FN reduziram significativamente os valores de microdureza. Por outro lado, o V-Print Dentbase, apesar de sofrer redução após o envelhecimento térmico, não obteve diferenças significativas relativamente aos valores iniciais, depois do químico. Na resistência à flexão, verificaram-se valores inferiores da V-Print Dentbase. A Denture 3D apresentou resultados de resistência à flexão superiores, sendo equiparável às resinas termopolimerizáveis. Conclusões: Existem diferenças entre materiais de diferente fabrico na microdureza inicial e após envelhecimento térmico e químico, sendo inferiores nas resinas impressas. Os envelhecimentos resultaram em alterações na microdureza apenas num material impresso. O material Denture 3D teve uma resistência à flexão semelhante aos convencionais, enquanto o V-Print Dentbase obteve valores inferiores.

http://doi.org/10.24873/j.rpemd.2022.01.941

\section{\#083 Microdureza e resistência à flexão de resinas CAD-CAM submetidas a envelhecimento térmico}

Mariana Fonseca*, Patrícia Rebelo, Joana Costa, Ana Bettencourt, Jaime Portugal, Cristina Bettencourt Neves

Faculdade de Farmácia da Universidade de Lisboa, Faculdade de Medicina Dentária da Universidade de Lisboa

Objetivos: O objetivo deste estudo in vitro foi avaliar a microdureza e a resistência à flexão, de resinas utilizadas para a confeção de bases de próteses dentárias, produzidas pelo método CAD-CAM de impressão 3D e submetidas a processos de envelhecimento térmico. Materiais e métodos: Um total de 32 espécimes retangulares $(4 \times 10 \times 3,3 \mathrm{~mm})$ foram fabricados, formando grupos $(n=8)$ de duas resinas fotopolimerizáveis de impressão 3D (V-Print Dentbase e Denture 3D) e duas resinas termopolimerizáveis convencionais (Probase Hot e Villacryl $\mathrm{H}$ Rapid FN). Todos os espécimes foram sujeitos a um envelhecimento térmico que consistiu em 1000 ciclos de oscilações térmicas entre os $5^{\circ} \mathrm{C}$ e os $55^{\circ} \mathrm{C}$. Foi realizada a medição da microdureza com uma ponta Knoop e a medição da resistência à flexão em 3 pontos. Resultados: Foram encontradas diferenças estatisticamente significativas entre as resinas estudadas nos valores de microdureza inicial $(p<0,001)$, após o envelhecimento térmico $(p<0,001)$ e nos valores de resistência à flexão $(p<0,001)$. Os valores de microdureza foram superiores para os grupos das resinas termopolimerizáveis convencionais antes e após o envelhecimento térmico. No grupo da resina impressa V-Print Dentbase, quando comparados os dois tempos de medição da microdureza, não foram observadas diferenças estatisticamente significativas $(p=0,064)$. Nos restantes grupos, os valores de microdureza foram inferiores após o envelhecimento térmico $(\mathrm{p}<0,001)$. Na resistência à flexão, a resina im- pressa V-Print Dentbase obteve valores significativamente inferiores $(p<0,05)$, não tendo sido observadas diferenças significativas entre os restantes grupos. Conclusões: As resinas CAD-CAM de impressão 3D apresentaram valores de microdureza inferiores às resinas convencionais termopolimerizáveis, antes e após o envelhecimento térmico. O envelhecimento térmico não teve influência nos valores de microdureza apenas na resina V-Print Dentbase. As resinas de impressão 3D obtiveram valores inferiores de resistência à flexão quando comparadas com as resinas termopolimerizáveis.

http://doi.org/10.24873/j.rpemd.2022.01.942

\#084 Tratamento térmico pós-polimerização e estabilidade cromática de resinas bis-acrílicas CrossMark

Beatriz Garcias Soares*, Mariana Maggessi Formosinho, Ana Filipa Chasqueira, Jaime Portugal

Faculdade de Medicina Dentária da Universidade de Lisboa

Objetivos: Avaliar o efeito de tratamento térmico pós-polimerização na estabilidade cromática de duas resinas bis-acrílicas. Materiais e métodos: Foi fabricado um total de 70 espécimes com a forma de disco (12x2 mm) e aleatoriamente divididos, de forma a estabelecer 14 grupos $(n=5)$. Foram criados 12 grupos experimentais de acordo com as combinações possíveis entre: resinas bis-acrílicas [Structur 3 (S3) e Protemp 4 (P4)]; tratamentos térmicos pós-polimerização [imersão em água a $60^{\circ} \mathrm{C}(-\mathrm{B})$, ação de microondas (700 W) (-M) e exposição a calor emitido por secador de cabelo $(2000 \mathrm{~W})(-\mathrm{S})]$; e duração do tratamento 2 min (-2) e 4 min (-4). Para cada resina, foi também criado 1 grupo controlo sem tratamento térmico pós-polimerização. A determinação dos parâmetros de cor (CIE Lab) foi realizada com espetrofotómetro VITA Easyshade V. A medição inicial que serviu de valor de referência foi determinada 15 minutos após o início da reação de polimerização de cada espécime. Os espécimes dos grupos experimentais foram submetidos à ação do calor, de acordo com a respetiva condição experimental, 30 min após o início da reação de polimerização. Todos os espécimes foram, de seguida, imersos numa solução de café. Os parâmetros de cor foram novamente determinados ao fim de 24 horas e 7 dias de imersão e, calculada a alteração cromática $(\triangle \mathrm{E} 00)$ relativamente à cor inicial. Os dados foram analisados com testes não paramétricos de Wilcoxon, Kruskal-Wallis e Mann-Whitney U $(\alpha=0,05)$. Resultados: $\mathrm{O} \triangle \mathrm{E} 00$ aumentou de forma estatisticamente significativa $(p<0,001)$ das $24 \mathrm{~h}$ para os 7 dias. O P4 apresentou valores de $\triangle E 00$ estatisticamente $(p<0,001)$ mais baixos que o S3. Apesar de não se terem verificado diferenças estatisticamente significativas $(p>0,05)$ entre os 3 tipos de tratamento térmico e entre os 2 períodos de duração destes, foram observadas algumas diferenças na comparação dos grupos experimentais com os respetivos grupos controlo. O P4-S-4 apresentou às 24 horas um $\triangle \mathrm{E} 00$ estatisticamente $(\mathrm{p}=0,022)$ menor que o controlo, e o S3-B-2 apresentou aos 7 dias um $\triangle \mathrm{E} 00$ estatisticamente $(p=0,048)$ mais elevado que o S3 sem tratamento térmico. Conclusões: A estabilidade cromática diminuiu com o aumento do tempo de imersão em café. A estabilidade cromática varia de acordo com a resina considerada. De uma for- 